\title{
Shedding Light on the Global Distribution of Economic Activity
}

\author{
Tilottama Ghosh ${ }^{*, 1}$, Rebecca L. Powell ${ }^{2}$, Christopher D. Elvidge ${ }^{3}$, Kimberly E. Baugh ${ }^{4}$, \\ Paul C. Sutton ${ }^{2}$ and Sharolyn Anderson ${ }^{2}$
}

${ }^{I}$ Cooperative Institute for Research in Environmental Sciences, University of Colorado, Boulder, USA; and Department of Geography, University of Denver, Denver, Colorado, USA

${ }^{2}$ Department of Geography, University of Denver, Denver, CO 80208, USA

${ }^{3}$ Earth Observation Group, Solar and Terrestrial Physics Division, NOAA National Geophysical Data Center, 325 Broadway, Boulder, CO 80305, USA

${ }^{4}$ Cooperative Institute for Research in Environmental Sciences, University of Colorado, Boulder, CO 80309, USA

\begin{abstract}
Collection of data on economic variables, especially sub-national income levels, is problematic, due to various shortcomings in the data collection process. Additionally, the informal economy is often excluded from official statistics. Nighttime lights satellite imagery and the LandScan population grid provide an alternative means for measuring economic activity. We have developed a model for creating a disaggregated map of estimated total (formal plus informal) economic activity for countries and states of the world. Regression models were developed to calibrate the sum of lights to official measures of economic activity at the sub-national level for China, India, Mexico, and the United States and at the national level for other countries of the world, and subsequently unique coefficients were derived. Multiplying the unique coefficients with the sum of lights provided estimates of total economic activity, which were spatially distributed to generate a spatially disaggregated $1 \mathrm{~km}^{2}$ map of total economic activity.
\end{abstract}

Keywords: Nighttime lights imagery, LandScan population grid, disaggregated map of total economic activity, informal economy.

\section{INTRODUCTION}

The Millennium Development Goals (MDG) was adopted by 189 nations during the United Nations Millennium Summit in September 2000. They set quantitative benchmarks with the goal of halving extreme poverty in all its forms by the target date of 2015. The eight MDG are as follows: 1) Eradicate extreme poverty, 2) Achieve universal primary education, 3) Promote gender equality and empower women, 4) Reduce child mortality, 5) Improve maternal health, 6) Combat HIV/AIDS, malaria and other diseases, 7) Ensure environmental sustainability, 8) Develop a global partnership for development. Some progress has been made towards the achievement of these goals. However, the global economic recession in the past year is proving (and will continue to prove) to be a major stumbling block, as many more people may plunge into poverty [1]. Understanding the global distribution of wealth and the economic well-being of the global population assumes immense importance in the context of achieving the MDGs and for implementing various policy decisions [2].

A nation's economic growth is typically measured in terms of Gross Domestic Product (GDP), i.e., the market value of all final goods and services produced in a given

*Address correspondence to this author at the Cooperative Institute for Research in Environmental Sciences, University of Colorado, Boulder, USA; Tel: 303-497-6385; Fax: 303-497-6513;

E-mails: tilottama.ghosh@noaa.gov, ghoshtilottama@hotmail.com countries country in a given year [3]. For a scientific understanding of the connections between the socioeconomic conditions of and their impacts on the physical environment, it is necessary to integrate socio-economic data with physical and environmental data. However, maps showing the distribution of wealth of countries in terms of GDP are usually available only at the national level. This prevents the integration of GDP maps with other physical and environmental data (e.g., global land cover/land use, elevation data, climate, soil, and vegetation data), which are usually only available in raster or grid formats (i.e., a matrix of cells or pixels organized in rows or columns). Disaggregated maps of economic activity (i.e., raster format) would facilitate its easy integration with other environmental and physical datasets across administrative boundaries [4]. The primary objective of this paper is to create a disaggregated map of economic activity from nighttime lights data for the year 2006. A major advantage of a disaggregated map is that economic data that are currently available only at national or state levels can be aggregated to various administrative units - national, state, sub-state, and municipal; or physical and ecological units, such as, watersheds, or soil and vegetation zones [5].

There are several challenges to the collection of high quality GDP data, including the absence of standardized national income accounting methods, different bureaucratic capacity of states, lack of consistent methodology in data collection, low levels of efficiency of surveyors, the subjective response of the responders in ground surveys, and the varying political and economic situation between 
countries $[6,7]$. Some countries do not even have national accounts data. For example, Iraq, Myanmar, Somalia, and Liberia, are the countries which were not included in the most recent version of the Penn World Tables 6.2. These data, provided by the Center for International Comparisons at the University of Pennsylvania, include purchasing power parity and national income accounts converted to international prices for 188 countries for some or all of the years between 1950-2004 [7]. For most developing countries, and even for a few developed countries, reliable economic data on output at the sub-national level, particularly for cities and even larger regions, are often not available [7]. Economists can also make grave mistakes in their estimates. In a recently reported New York Times article [8], economists recognized a mistake in their estimation of the size of the Chinese economy as four trillion dollars greater than what it really was (10 trillion dollars, rather than six trillion dollars) due to poor choices of Purchasing Power Parity (PPP). More importantly, in many developing countries, a greater percentage of economic activity is conducted within the informal sector than the formal sectors, and informal sector productivity is often excluded from the formal statistics [7, 9-11].

Changes in the global economy associated with the growth and expansion of capitalism, global integration and competition because of globalization, and the global recession of the past year have caused many more millions of people to join the informal workforce. Available statistics show that informal workers comprise a substantial proportion of the employed workforce in both developed and developing countries, and their numbers are much larger than most people realize them to be. They also contribute substantially towards GDP. Moreover, there is a significant overlap between informal employment and the population in poverty. Considering the importance of the informal economy, the economic performance of a country can only be modeled or predicted if the value of the informal economy to the total output of the country is adequately measured and valued. Superior statistics would enable policy makers to better comprehend the contributions of informal economy to economic growth and the relationship between informal employment arrangements and poverty [12]. This paper presents a model for estimating total (formal plus informal) economic activity from nighttime lights imagery collected globally.

Remote sensing data in the form of nighttime lights can provide a uniform, consistent, and independent estimate of economic activity $[4,13]$. The striking correlation between the spatial distribution of nighttime lights and economic activity has been utilized in several studies for estimating economic activity at the national and sub-national level [7, 911, 14]. Doll et al. [15] created the first global disaggregated map of GDP at one degree resolution based upon a log-linear relationship between lit urban areas and official Purchasing Power Parity (PPP) GDP for 46 countries. The map was created by using a six-month composite of stable lights data for 1994-95. That study estimated the total GDP of the world to be 22.1 trillion dollars, or about 80 percent of the World Resource Institute's International dollar value of 27.7 trillion dollars for 1992. However, Doll et al. [15] did not show predicted GDP for individual countries. They also recognized that the use of radiance-calibrated nighttime lights data, as well as inclusion of the contributions from the agricultural, industrial, and service sectors, could provide much better results. Sutton and Costanza [16] used the radiance-calibrated image of 1996-97 to create a 30 arcsecond (approximately, $1 \mathrm{~km}^{2}$ ) grid of global marketed economic activity. They did this based on simple, nationally specific ratios of GDP to light energy (LE) for each nation of the world and applied it to a global nighttime satellite image to create an image of \$GDP per year per $\mathrm{km}^{2}$.

Doll et al. [15] used the 1996-97 radiance-calibrated image to create estimated GDP maps of the United States and 11 European Union countries at 5-km resolution using linear relationships between total radiance and Gross Regional Product (GRP). Through their analysis, they also highlighted a number of potential areas for improvement and further investigation. They relied only on measured nighttime lights to distribute economic activity. Although this is a rational assumption for countries where industry and service sectors comprise 90 percent of the economy, the assumption may not be valid for countries where agriculture comprises a larger section of the national economy. Also, maps based only on lights do not consider the spatial distribution of agricultural productivity, but rather consider agricultural economic activity as simply another node of economic activity; that is, the resulting map locates agricultural productivity in the towns which emit light and not in the fields where crops are grown.

We build upon these previous attempts at creating global grids of economic activity, from nighttime lights data with the goal of addressing the drawbacks of the previous studies. Specifically, the goal of the current study was to generate a unique relationship between lights within an administrative unit (states of China, India, Mexico, and the U.S., and other countries of the world) and Gross State Product (GSP) or Gross Domestic Product (GDP) of that unit. This was initially based on log-linear relationship between the sum of light intensity values and official GSP or GDP values, which has been exploited in a number of previous studies. Through further analysis, unique coefficients $\left(\beta_{i}{ }^{\prime}\right)$ were derived for each administrative unit. These unique coefficients were multiplied by the sum of lights of the associated unit to estimate total economic activity for that administrative unit (Equations 1 and 2). Because we assumed that when the sum of lights equals zero, GSP or GDP also equals zero, the relationship was represented as follows:

$\beta_{\mathrm{i}}{ }^{\prime} \mathrm{x} \mathrm{SL}_{\mathrm{i}}=\mathrm{GSPI}_{\mathrm{i}}$
$\beta_{\mathrm{i}}{ }^{\prime} \mathrm{x} \mathrm{SL}_{\mathrm{i}}=\mathrm{GDPI}_{\mathrm{i}}$

where, $\mathrm{SL}_{\mathrm{i}}$ is the sum of lights of each administrative unit $\mathrm{i}$; $\beta_{\mathrm{i}}{ }^{\prime}$ is the estimated unique coefficient for each administrative unit $\mathrm{i}$; $\mathrm{GSPI}_{\mathrm{i}}$ is the total estimated (formal plus informal) economic activity for each state of China, India, Mexico, and the U.S.; GDPI is the total estimated (formal plus informal) economic activity for each country $i$.

The estimated GSPI $_{i}$ and GDPI $_{i}$ values were spatially distributed within each administrative unit using the percentage contribution of agriculture towards GDP for each country, combined with raster representations of the nighttime lights image and the LandScan population grid. Specifically, the percentage of total estimated economic activity attributed to agriculture was spatially distributed 
according to the LandScan population grid, and the percentage of economic activity attributed to commercial/industrial sectors was distributed according to the nighttime lights imagery.

\section{DATASETS}

\subsection{Nighttime Lights Imagery}

The nighttime lights image was used to calculate the sum of light intensity values for each administrative unit and to distribute the percentage of total estimated economic activity not attributed to agriculture (in other words, attributed to commercial/industrial activity) for each administrative unit. A merged stable lights and radiance-calibrated nighttime image of 2006 was used to estimate total economic activity of each administrative unit. The National Geophysical Data Center (NGDC) of the National Oceanic and Atmospheric Administration (NOAA) has been archiving and processing Defense Meteorological Satellite Program's Operational Linescan System (DMSP-OLS) nighttime lights data since 1994. The 2006 stable lights data were composited from a set of cloud-free orbits for the year 2006, with the ephemeral light sources, such as fires and lightning removed [13]. The main problem associated with the DMSP stable lights data is the saturation of data in city centers and other brightly lit zones. The radiance-calibrated image of 2006 was produced by combining three images collected at three different fixed gain settings. The radiance-calibrated image helps to overcome the problem of saturation of city centers and provides a much better image of the internal structure of cities by highlighting spatial detail associated with brightness variations within urban centers [17]. Blending the stable lights data and the combined radiance-calibrated image made it possible to accommodate the best features of both types of nighttime images.

The spatial resolution of the original nighttime lights data is $2.7 \mathrm{~km}$. The images are geolocated to 30 arc-second grids, equivalent to approximately $1 \mathrm{~km}^{2}$ at the equator. The latitudinal extent of the dataset is from $75^{\circ} \mathrm{N}$ to $65^{\circ} \mathrm{S}$ and the longitudinal extent is from $180^{\circ} \mathrm{W}$ to $180^{\circ} \mathrm{E}$ (Fig. 1).

\subsection{LandScan Population Grid}

The LandScan population grid of 2006 was used to distribute the percentage of total economic activity contributed by agriculture for each administrative unit. The U.S. Department of Energy at Oak Ridge National Laboratory has produced a progressive series of spatially disaggregated global population count datasets. The LandScan model uses spatial data and image analysis techniques, along with multi-variable dasymetric modeling approach, to apportion sub-national level census counts to each grid cell based on proximity to roads, slope, land cover, and other information, within an administrative boundary. The cells have integer population counts representing ambient population distribution, that is, a population estimation that takes into account the movement of people for work or travel and not only where people sleep. The dataset has a spatial resolution of 30 arc-seconds [18]. For this analysis, the northern latitudinal extent of the LandScan data was cropped to $75^{\circ} \mathrm{N}$ (originally extends to $84^{\circ} \mathrm{N}$ ) and the southern latitudinal extent was cropped to $65^{\circ} \mathrm{S}$ (originally extends to $90^{\circ} \mathrm{S}$ ) to match with the latitudinal extent of the nighttime lights data (Fig. 2).

\subsection{Official Gross Domestic Product (GDP) and Gross State Product (GSP) Data}

Official GDP and GSP data for each respective administrative unit, with added informal economy estimates, were used to calibrate the sum of lights to predict total economic activity through regression models for groups of administrative units. Official GDP data were obtained from the 2008 World Development Indicators for all available countries [19]. For most of the countries, the data were for the year 2006, but for a few countries 2006 data were not available, and 2005 GDP data were used. Data for a few of

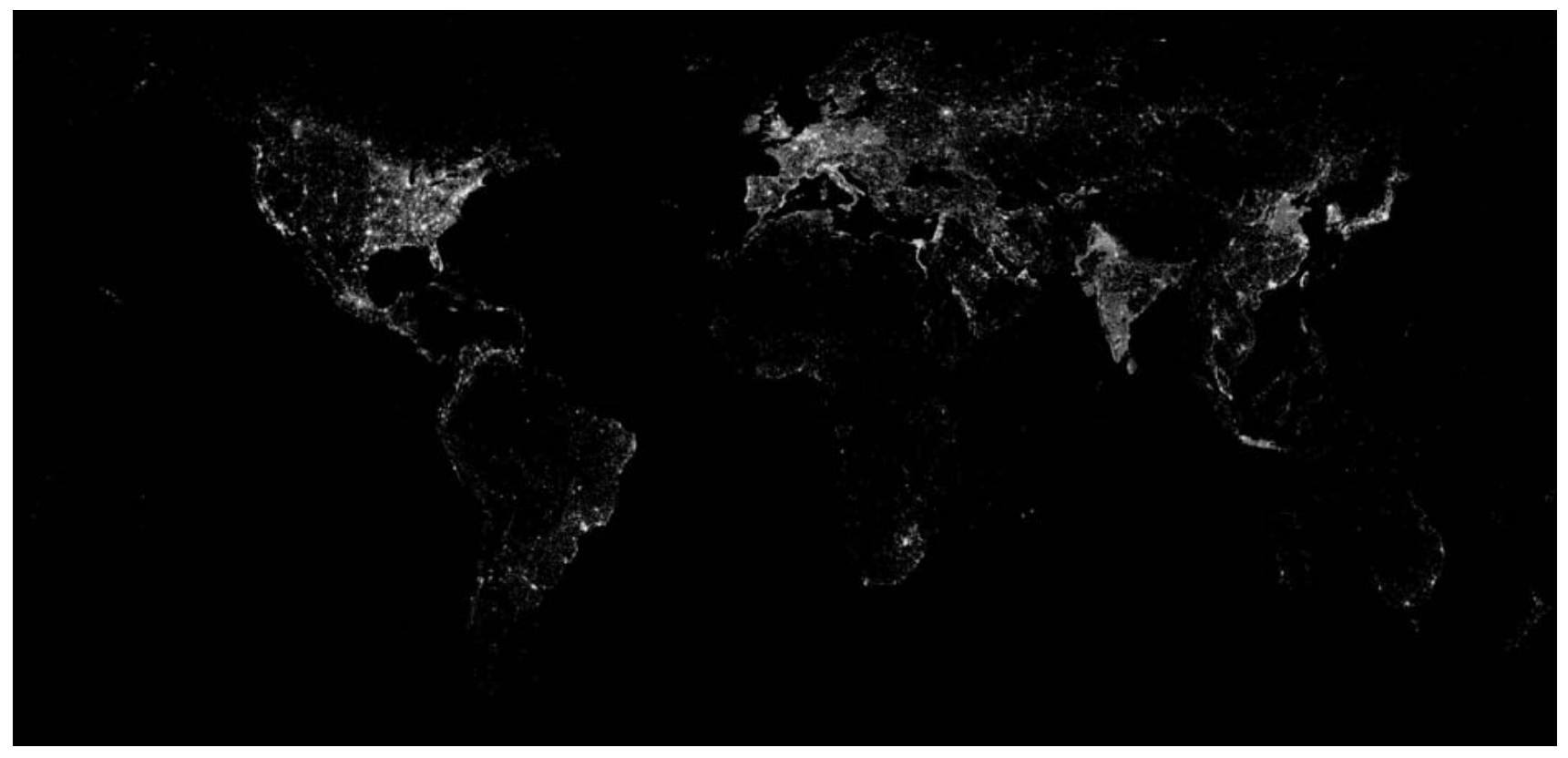

Fig. (1). Merged stable lights and radiance-calibrated image of 2006. 


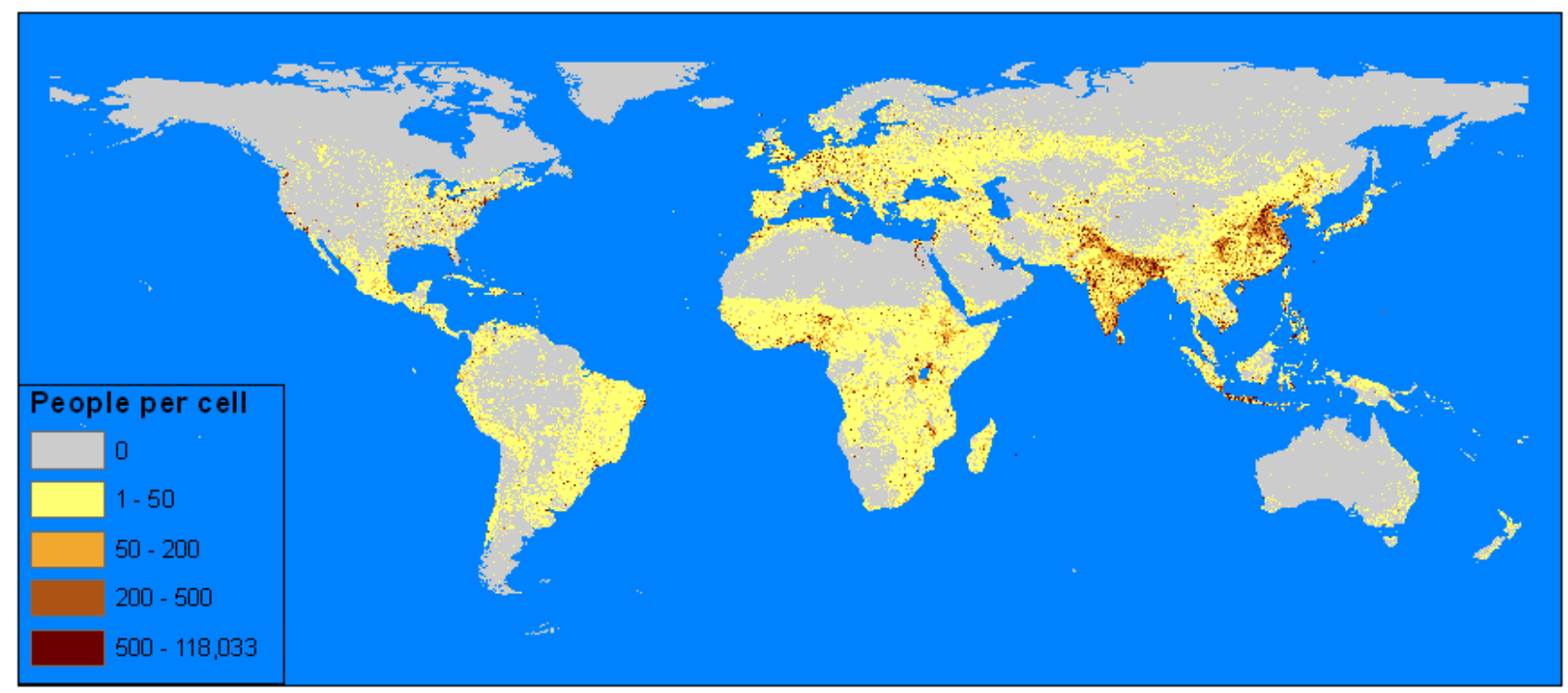

Fig. (2). LandScan Population grid, 2006.

the countries were not available from the World Development Indicators, and for those countries, data were taken from the Central Intelligence Agency (CIA) World Factbook [20]. All official GDP data were expressed in Purchasing Power Parity (PPP) U.S. dollars. The PPP figure makes international comparisons possible, as it attempts to address the fluctuations in country exchange rates by expressing the quantity of goods and services each currency can buy locally as one dollar would buy in the U.S. [21].

The Gross State Product (GSP, i.e., GDP at the state level) of the U.S., Mexico, China, and India, were obtained from the statistical organizations of the respective countries. For the U.S., data were obtained from the U.S. Bureau of Economic Analysis [22]; for Mexico, from Instituto Nacional de Estadistica Geografia [23]; for the provinces, municipalities, autonomous regions, and Special Administrative Regions of China, from the National Bureau of Statistics of China [24]; and for India, from the Central Statistical Organization [25]. All the data were for the year 2006 and were converted into PPP U.S. dollars by using the PPP conversion factors for that year.

\subsection{Informal Economy Data}

The informal economy is present in both the developed and developing countries [12]. Almost no official national GDP statistics take into account the contribution of informal economy. Different direct and indirect approaches for estimating the contribution of informal economy towards GDP exist. The dynamic multiple-indicators multiple-causes model (DYMIMIC) developed by Schneider [26] is different from all the other approaches because it considers multiple causes leading to the existence and growth of informal economy, as well as multiple effects of the informal economy over time. In this model, the hidden economy is estimated as an unobserved variable over time through a factor-analytic approach. The three main causes of informal economy as distinguished by the model are as follows: high taxation, heavy regulation and declining "tax morality" (i.e., citizen's attitude towards the state). According to the model, the changes in the size of the informal economy are reflected by the following indicators: (a) monetary indicators - if activities in the informal economy rise, additional monetary transactions are required; (b) labor market indicators increased participation of workers in the hidden sector would result in decreased participation in the official economy; and lastly, (c) production market indicators - when there is an increase of informal economy activity, inputs (especially labor) move out from the official economy and this displacement can have an overall depressing effect on the official growth of the economy [27].

Schneider [26] used the DYMIMIC model to estimate the informal economy (which he calls the shadow economy) as a percentage of "official" GDP for 145 countries, including developing, transition, and highly developed Organization for Economic Co-operation and Development (OECD) economies, over the period between 1999 and 2005. He provided revised estimates for 21 OECD countries over the period between 1989 and 2009 [28] and 25 transition countries over the period between 1999 and 2007 [29]. Thus, 2005 percentage estimates of the informal economy were available for the 96 developing countries, and 2006 percentage estimates were available for the 21 OECD and 25 transition countries. In the present study, the percentage informal economy estimates were added to the GDP of each country $\left(\mathrm{GDPS}_{\mathrm{i}}\right)$ to develop the regression model to calibrate the sum of lights. However, since state level estimates of informal economy were not available, the country level estimates of the percentage informal economy for China, India, Mexico, and the U.S. were added to the state GSP values $\left(\mathrm{GSPS}_{\mathrm{i}}\right)$.

\subsection{Percentage Contribution of the Agricultural Sector}

Agriculture is an important component of economic activity, especially in many of the developing countries. The nighttime lights imagery does not account for the percentage of economic activity contributed by agriculture, as this percentage is distributed in the darker areas of the nighttime lights images (corresponding to non-urban land use). Thus, 
the percentage contribution of estimated total economic activity attributed to agriculture was spatially distributed according to the LandScan population grid based on the assumption that rural populations living in those dark areas contribute to economic activity (mainly through agricultural activities), although they are not captured in the nighttime lights image. Data on the percentage contribution of agriculture towards GDP at the national level was acquired from the World Development Report of 2008 [30] and from the CIA World Factbook [20]. The percentage contribution of the agricultural sector towards GDP were not available at the state level, and therefore the country level percentages for the four countries (China, India, Mexico, and the U.S.) were used to estimate the contribution of the agricultural sector towards GSP for each state.

\section{METHOD}

The creation of the disaggregated map of total (formal plus informal) economic activity involved two distinct parts. In the first part, we estimated total economic activity for each administrative unit $\left(\mathrm{GSPI}_{\mathrm{i}}\right.$ or $\left.\mathrm{GDPI}_{\mathrm{i}}\right)$ by multiplying the sum of lights (i.e., sum of brightness values of lights for all lit areas) of each administrative unit by a unique coefficient (Equations 1 and 2). The second part involved spatially

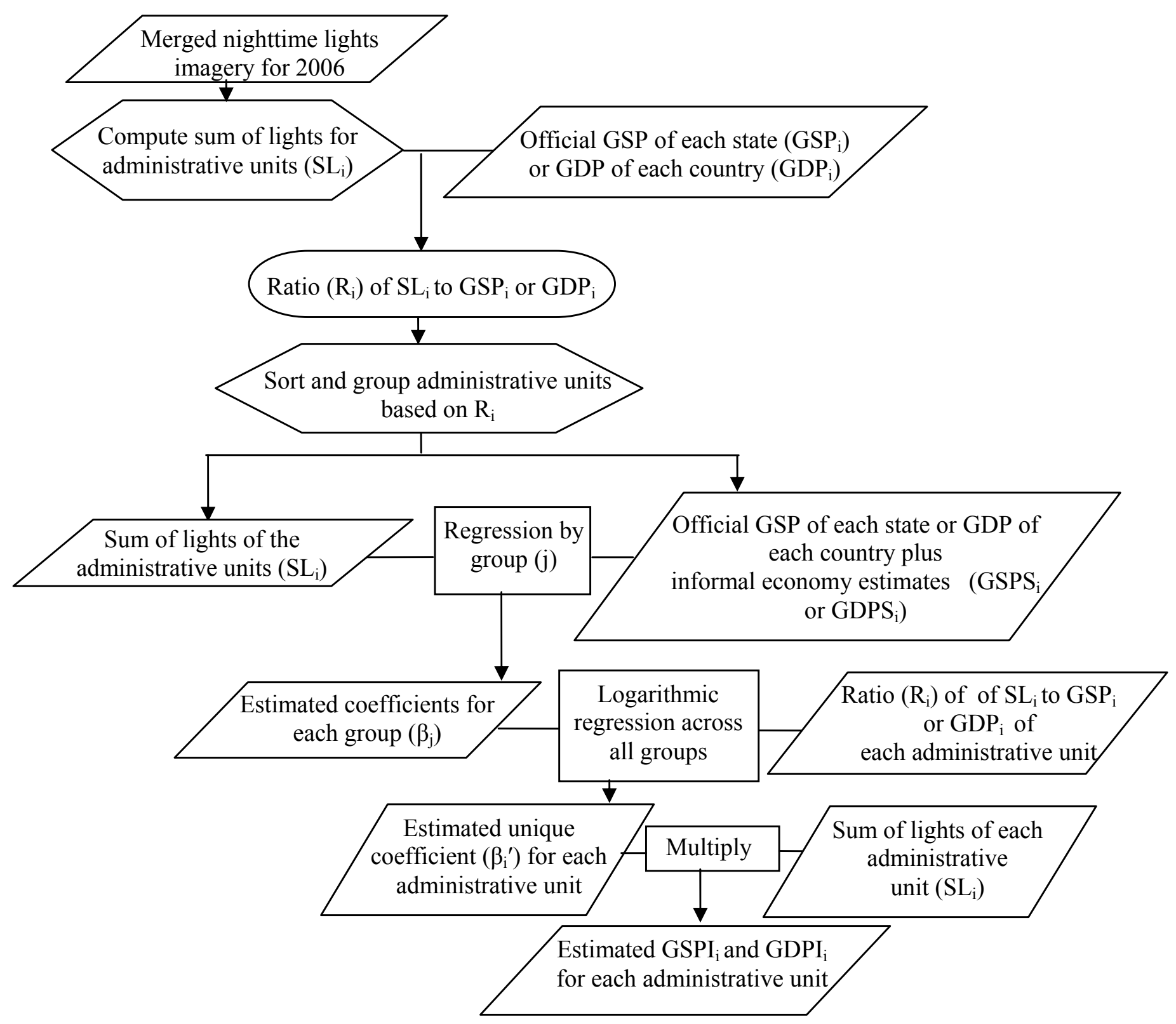

Fig. (3). Flow diagram showing the steps involved in estimating $\mathrm{GSPI}_{\mathrm{i}}$ for each of the states of China, India, Mexico, and the United States and $\mathrm{GDPI}_{\mathrm{i}}$ for each country. 
distributing the estimated total economic activity $\left(\mathrm{GSPI}_{\mathrm{i}}\right.$ and GDPI ${ }_{i}$ ) of each administrative unit into $1 \mathrm{~km}^{2}$ grid cells based on the percentage contribution of agriculture, the nighttime lights image, and the LandScan population grid.

\subsection{Estimating Total Economic Activity for Administrative Units (GSPI $I_{i}$ and GDPI $\left._{\mathrm{i}}\right)$}

The steps involved in the first part of the analysis are shown in the flow diagram of Fig. (3).

The first step towards estimating unique coefficients involved computing the sum of light intensity values within each of the administrative units $\left(\mathrm{SL}_{\mathrm{i}}\right)$ from the merged nighttime lights image of 2006. The sum of lights was calculated at the sub-national level for China, India, Mexico, and the U.S. to reduce the influence of these 'outlier' countries, which have the greatest weight in increasing the $\mathrm{R}^{2}$ - value when the sum of lights is regressed against official GDP of all countries. Moreover, official GSP data were easily available for these four countries. Regression analysis between the sum of lights $\left(\mathrm{SL}_{\mathrm{i}}\right)$ and official $\mathrm{GDP}_{\mathrm{i}}$ or $\mathrm{GSP}_{\mathrm{i}}$ value for each administrative unit was conducted, and it was observed that a given administrative unit may be brighter or dimmer in comparison to what was expected based on officially reported $\mathrm{GSP}_{\mathrm{i}}$ or $\mathrm{GDP}_{\mathrm{i}}$ values (i.e., fall above or below the best-fit regression line). As is seen in Fig. (4), countries such as Japan and Germany are much wealthier relative to their sum of lights value; on the other hand, Russia is much poorer relative to its sum of lights value. Also, this relationship provided only a moderately strong $\mathrm{R}^{2}$ value of 0.73 .

This observation indicated that better relationships between the sum of lights $\left(\mathrm{SL}_{\mathrm{i}}\right)$ and $\mathrm{GSP}_{\mathrm{i}}$ or $\mathrm{GDP}_{\mathrm{i}}$ could be obtained if administrative units having similar ratios $\left(\mathrm{R}_{\mathrm{i}}\right)$ between sum of lights $\left(\mathrm{SL}_{\mathrm{i}}\right)$ and $\mathrm{GSP}_{\mathrm{i}}$ or $\mathrm{GDP}_{\mathrm{i}}$ were grouped together.

Next, ratios $\left(\mathrm{R}_{\mathrm{i}}\right)$ of the sum of lights $\left(\mathrm{SL}_{\mathrm{i}}\right)$ to the official $\mathrm{GSP}_{\mathrm{i}}$ or $\mathrm{GDP}_{\mathrm{i}}$ for each administrative unit were calculated as follows:

$\mathrm{R}_{\mathrm{i}}=\mathrm{SL}_{\mathrm{i}} / \mathrm{GSP}_{\mathrm{i}}$

or, $\mathrm{R}_{\mathrm{i}}=\mathrm{SL}_{\mathrm{i}} / \mathrm{GDP}_{\mathrm{i}}$

The ratios helped to group the administrative units in terms of their relationship between official GSP or $_{i} \mathrm{GDP}_{\mathrm{i}}$ and brightness values. The lower the ratio, the dimmer the administrative unit is relative to the level of economic development as measured from its official $\mathrm{GSP}_{i}$ or $\mathrm{GDP}_{\mathrm{i}}$ statistics, and the higher the ratio, the brighter the administrative unit is relative to the level of economic development as measured from its official $\mathrm{GSP}_{\mathrm{i}}$ or $\mathrm{GDP}_{\mathrm{i}}$ statistics. Fig. (5) presents a map of the ratio of sum of lights $\left(\mathrm{SL}_{\mathrm{i}}\right)$ to $\mathrm{GSP}_{\mathrm{i}}$ or $\mathrm{GDP}_{\mathrm{i}}$ of the administrative units.

After calculating the ratios $\left(\mathrm{R}_{\mathrm{i}}\right)$, the administrative units were sorted in ascending order. There were 392 administrative units in all, and units were binned in groups of twenty with 10 overlapping units in each subsequent group. This resulted in 36 groups of overlapping administrative units. Categorizing the administrative units based on these ratios helped to refine the coefficients for each group. Although administrative units in each group represented different levels of economic development, they fell within the specific range of lighting to GSP or GDP.

After grouping the administrative units based on the ratios $\left(\mathrm{R}_{\mathrm{i}}\right)$, the sum of lights $\left(\mathrm{SL}_{\mathrm{i}}\right)$ were calibrated to the

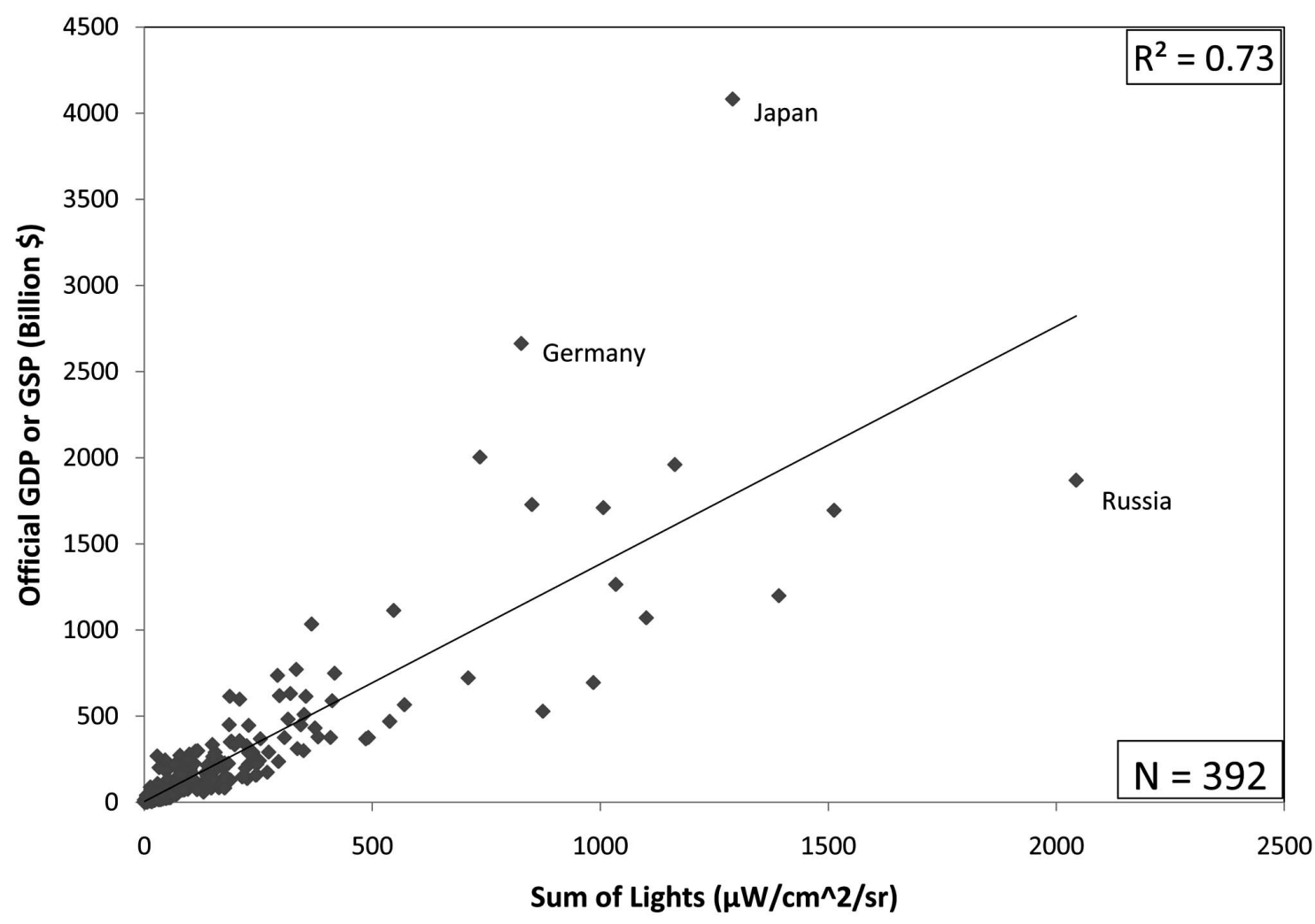

Fig. (4). Relation between sum of lights $\left(\mathrm{SL}_{\mathrm{i}}\right)$ and official GSPi or GDPi of the administrative units. 


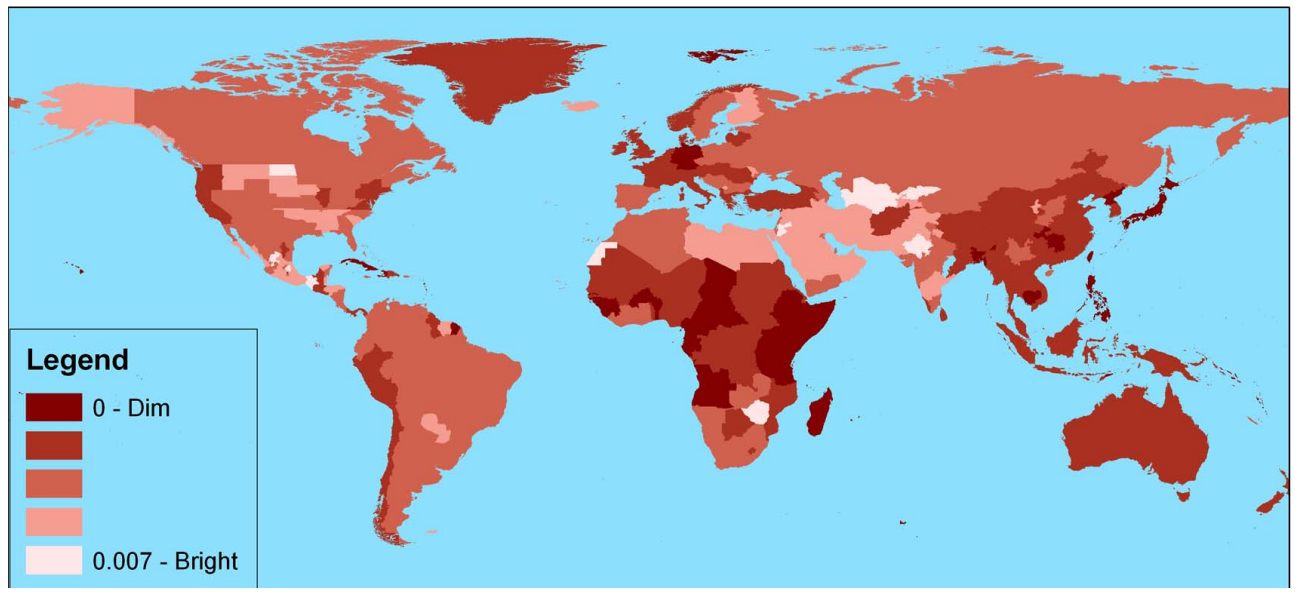

Fig. (5). Map of the ratio of sum of lights $\left(\mathrm{SL}_{\mathrm{i}}\right)$ to $\mathrm{GSP}_{\mathrm{i}}$ or $\mathrm{GDP}_{\mathrm{i}}$ for each administrative unit.

official $\mathrm{GSP}_{\mathrm{i}}$ or $\mathrm{GDP}_{\mathrm{i}}$ with added informal economy estimates (i.e., $\mathrm{GSPS}_{\mathrm{i}}$ or $\mathrm{GDPS}_{\mathrm{i}}$ ) $[26,28,29]$ through regression models for each of the 36 groups. The intercept was set to zero, based on the assumption that GSPS $_{\mathrm{i}}$ or GDPS $\mathrm{S}_{\mathrm{i}}$ should be zero when the sum of lights $\left(\mathrm{SL}_{\mathrm{i}}\right)$ was zero. Coefficients of determination $\left(\mathrm{R}^{2}\right)$ greater than 0.9 was obtained for all 36 groups by modeling the $\mathrm{SL}_{\mathrm{i}}$ as a linear function of $\mathrm{GSPS}_{\mathrm{i}}$ or GDPS $_{\mathrm{i}}$. The regression models provided beta coefficients $\left(\beta_{\mathrm{j}}\right)$ for each group (where $\mathrm{j}$ refers to the group index). Fig. (6) shows a subset of the regression models for the groups of administrative units, where group 1 has the lowest $R_{i}$ values, and the $36^{\text {th }}$ group has the highest $R_{i}$ values.

Next, through experimentation of relationships between the different variables, an empirical relationship was observed between the ratios $\left(R_{i}\right)$ of each administrative unit and the estimated coefficients $\left(\beta_{\mathrm{j}}\right)$ across all groups. For each successive group, the ratios of the overlapping last 10 administrative units and the coefficient value of the group in which the overlapping administrative units fell were used to depict the relationship. This relationship is described by a natural logarithmic function between these two variables (Equation 5). Exponentiating $\ln \left(\beta_{\mathrm{j}}\right)$ provided unique coefficients for each of the administrative units $\left(\beta_{\mathrm{i}}{ }^{\prime}\right)$ (Equation 6).

$$
\begin{aligned}
& \ln \left(\beta_{\mathrm{j}}\right)=0.58-0.95 * \ln \left(\mathrm{R}_{\mathrm{i}}\right) \\
& \beta_{\mathrm{i}}{ }^{\prime}=\operatorname{Exp}\left(0.58-0.95 * \ln \left(\mathrm{R}_{\mathrm{i}}\right)\right)
\end{aligned}
$$

There were a few outliers in the observed logarithmic relationship. The outliers which were dimmer than expected can be grouped into three categories as follows: (a) Small islands, such as, Solomon Islands, Maldives, and Bermuda; (b) extremely underdeveloped countries such as North Korea, Equatorial Guinea, Chad, Rwanda; and (c) city states, such as Hong Kong, District of Columbia. Each of these administrative units fell in the same group when they were categorized according to their ratios $\left(\mathrm{R}_{\mathrm{i}}\right)$. The only outlier that was much brighter relative to its official $\mathrm{GDP}_{\mathrm{i}}$ value was Zimbabwe. Outliers were excluded (leaving a total of 345 administrative units) when the logarithmic model was developed, but the resulting log-log regression model was used to estimate the unique coefficients for the outlier administrative units too. The logarithmic regression graph is shown in Fig. (7).
After the derivation of the estimated unique coefficient for each administrative unit $\left(\beta_{\mathrm{i}}{ }^{\prime}\right)$, the total economic activity $\left(\mathrm{GSPI}_{\mathrm{i}}\right.$ and $\left.\mathrm{GDPI}_{\mathrm{i}}\right)$, for each administrative unit was estimated by multiplying the sum of lights of each administrative unit $\left(\mathrm{SL}_{\mathrm{i}}\right)$ by its unique coefficient $\left(\beta_{\mathrm{i}}{ }^{\prime}\right)$ (Equations 1 and 2). The estimated $\mathrm{GSPI}_{\mathrm{i}}$ or GDPI $\mathrm{G}_{\mathrm{i}}$ includes both the formal and informal economies, and these values are represented in Fig. (8).

\subsection{Creating a Disaggregated Map of Total Economic Activity}

The second part of the analysis involved spatially distributing the estimated total economic activity to create a grid with a spatial resolution of 30 arc-seconds. A grid of agricultural economic activity was created by distributing the percentage contribution of agriculture towards economic activity for the administrative unit according to the LandScan population grid. A grid of non-agricultural economic activity was created by distributing the percentage of economic activity attributed to the commercial/industrial sector according to the nighttime lights. The grids of agricultural and non-agricultural economic activity were added to generate the grid of total economic activity.

To illustrate this process, we used a hypothetical country that has an estimated GDPI of $\$ 10,000$, total population of 500 , and a sum of lights value of 50 . The percentage contribution of agriculture towards GDP for that country was assumed to be 20 percent. First, we created a grid of agricultural activity. This was done by distributing the economic activity attributed to agriculture (i.e., $\$ 2,000$, in this example) according to the proportion of the population in each pixel of the LandScan population grid to the total population of the country (i.e., 500). Second, the grid of nonagricultural (or commercial or industrial) economic activity was created by distributing the remaining amount of GDPI (i.e., $\$ 8,000$ ) according to the proportion of the brightness value of lights in each pixel of the nighttime lights grid to the sum of light value (i.e., 50) for the whole country. Finally, the disaggregated map of total economic activity was produced by adding the two grids of agricultural and nonagricultural economic activity for each administrative unit. The model is illustrated in Fig. (9). 


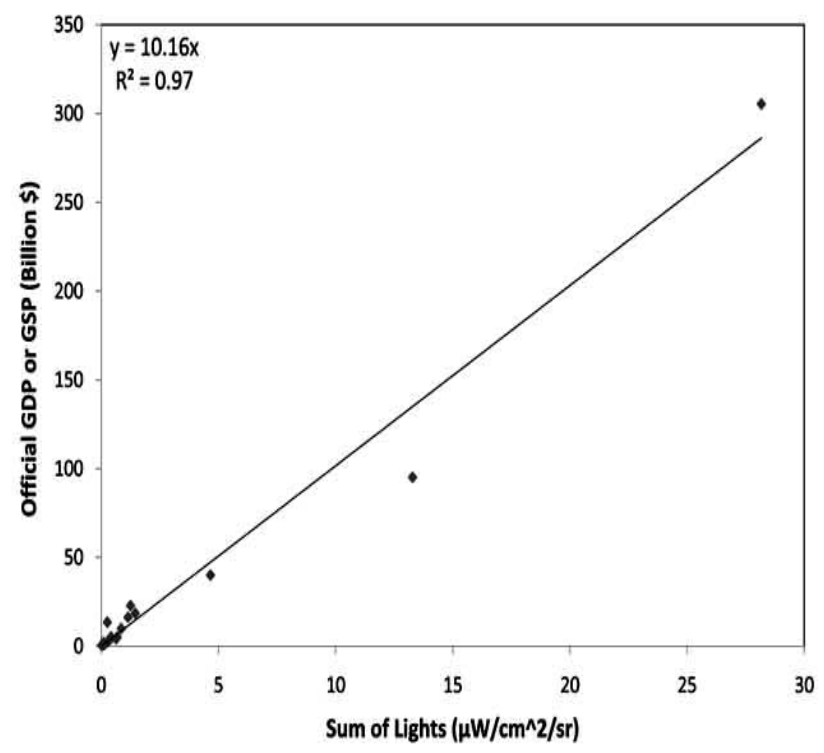

First Group

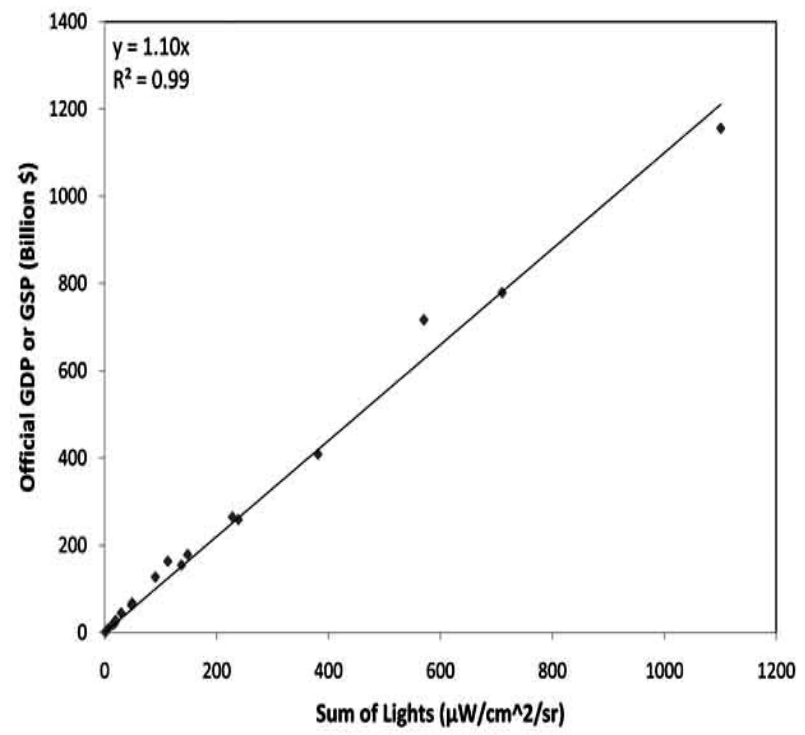

Twenty-Fifth Group

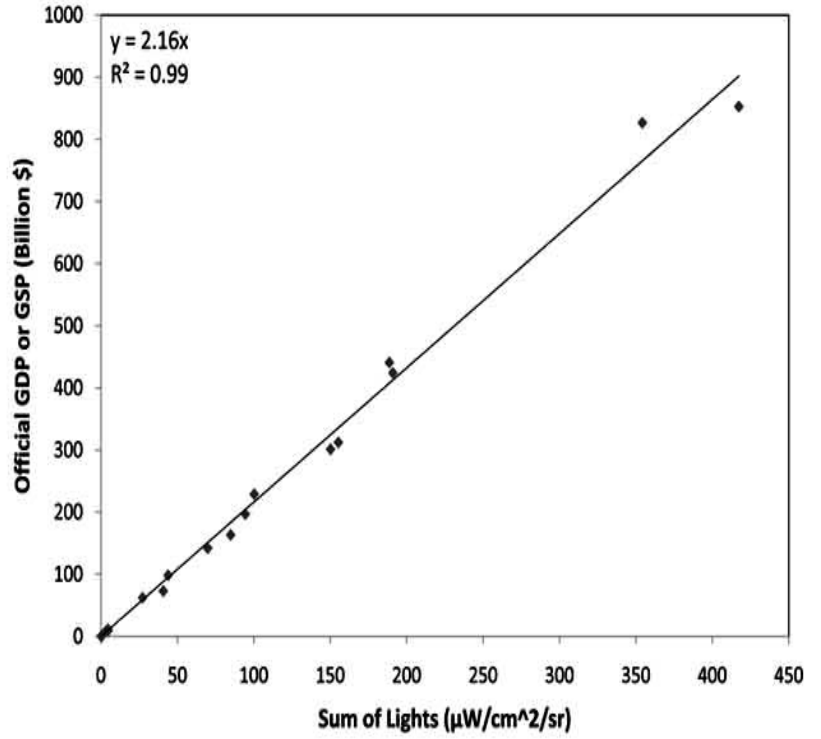

Thirtheenth Group

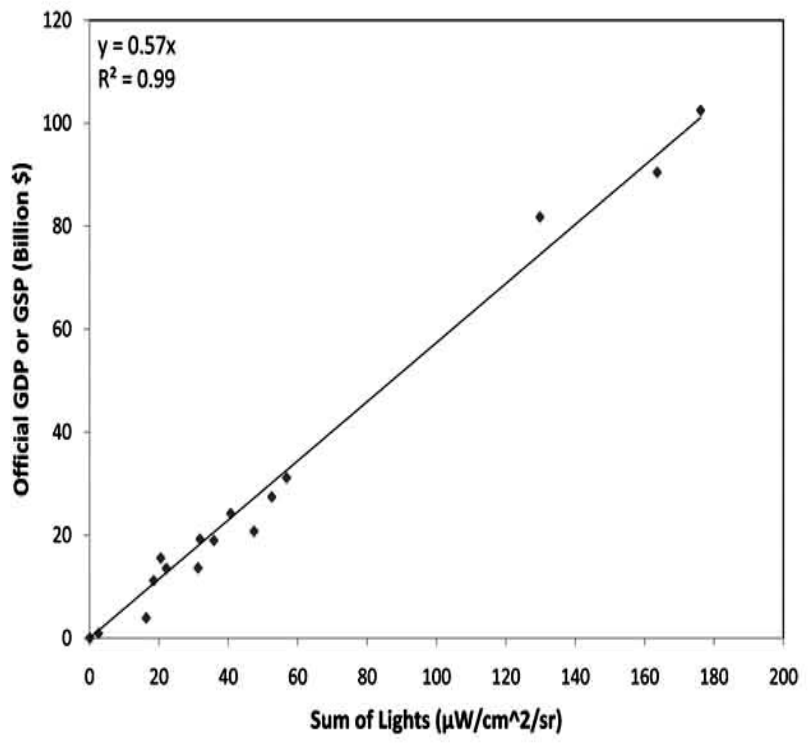

Thirty-Sixth Group

Fig. (6). Regression models for estimating coefficients for sample groups.

The model shown in Fig. (9) was applied globally to generate the disaggregated map of total economic activity (Fig. 10). The disaggregated map represents values in millions of dollars assigned to $1 \mathrm{~km}^{2}$ pixels, or millions of dollar per $\mathrm{km}^{2}$ (i.e., $\$ \mathrm{Mn} / \mathrm{km}^{2}$ ). The pixels with a $\$ 0$ value coincide with mountainous areas, deserts, and other inaccessible areas of continents. The pixels with the highest dollar values $\left(\$ 500-\$ 1278 \mathrm{Mn} / \mathrm{km}^{2}\right)$ lie in Singapore. Some of the richest cities of the world -New York City, Washington, D.C., Chicago, Los Angeles, Mexico City, London, Paris, Tokyo, and Hong Kong, have dollar values above $\$ 200 \mathrm{Mn} / \mathrm{km}^{2}$. Most of the urban areas of the world, such as capital cities and other major cities have dollar values ranging between $\$ 20$ and $\$ 200 \mathrm{Mn} / \mathrm{km}^{2}$. Fig. (11a-d) shows the disaggregated map of economic activity for the North-eastern U.S., South-western California, Japan, and Mexico City and surrounding areas.

There is no way to validate the disaggregated map of economic activity other than comparing it with the aggregated official GSP values at the sub-national level for China, India, Mexico, and the U.S., and GDP values for the other countries, as official GDP and GSP values are easily available only at the national level and occasionally at the 


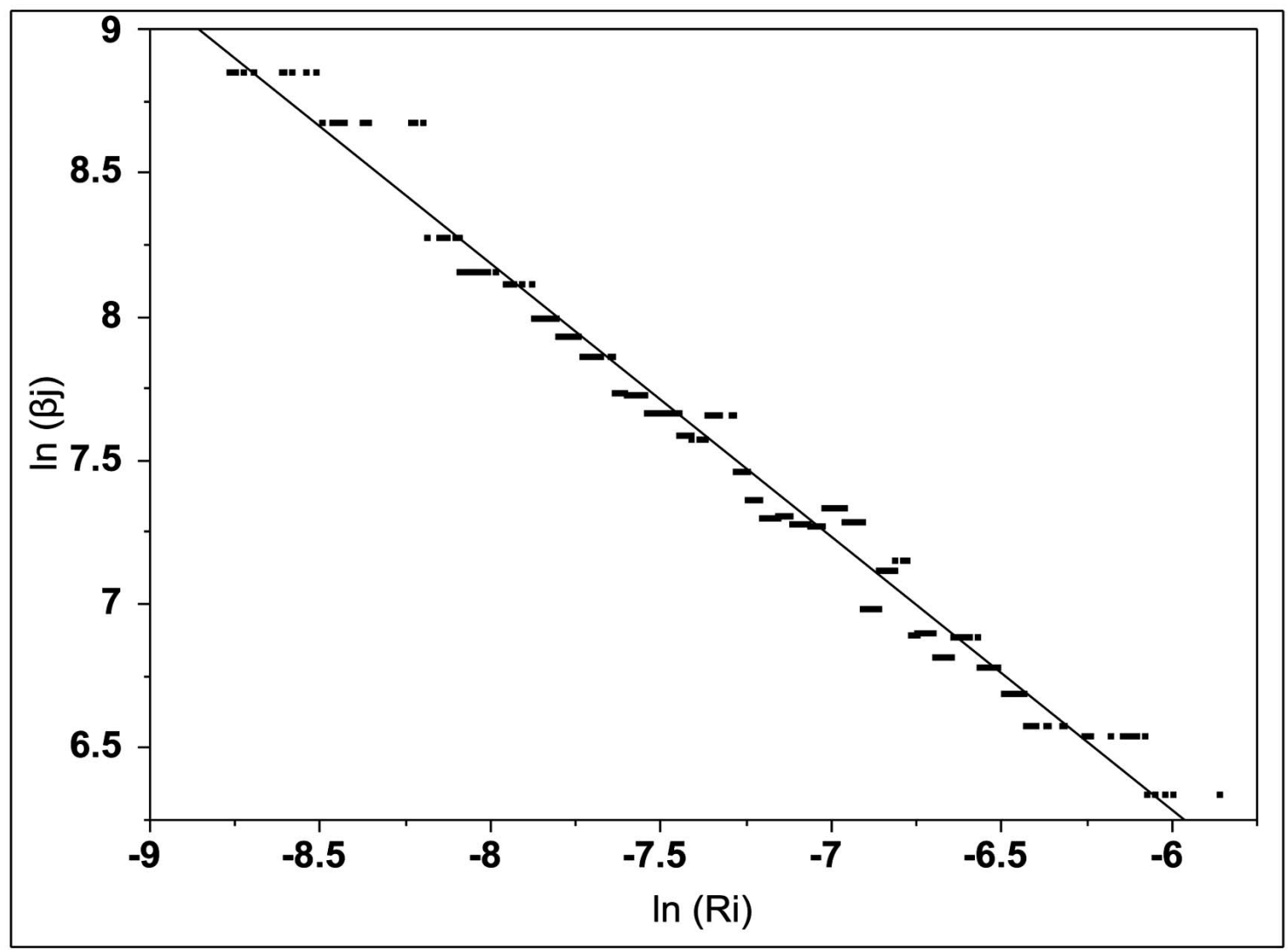

Fig. (7). The logarithmic regression to derive estimated unique coefficients, where $R_{i}=$ ratio of sum of lights to GSP or GDP and $\beta_{j}=$ Estimated group coefficient.

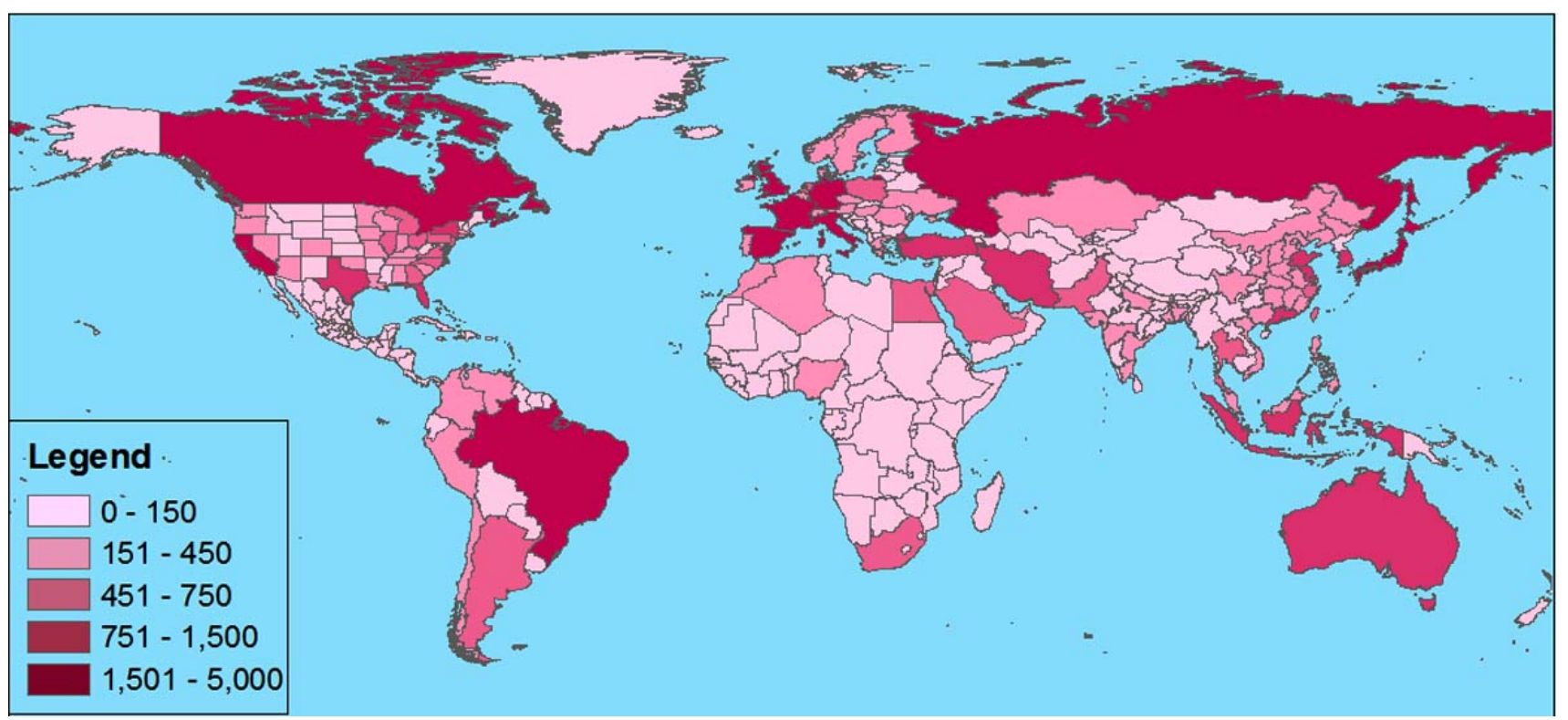

Fig. (8). Estimated GSPI ${ }_{i}$ for the states of China, India, Mexico, and the United States, and GDPI for other countries in billions of U.S. dollars.

sub-national level. Thus, the disaggregated map of estimated total economic activity was aggregated to the country level and the state level (Fig. 8). Two difference maps were created, one comparing the estimated total economic activity $\left(\mathrm{GSPI}_{\mathrm{i}}\right.$ and $\left.\mathrm{GDPI}_{\mathrm{i}}\right)$ and official economic activity $\left(\mathrm{GSP}_{\mathrm{i}}\right.$ and
$\mathrm{GDP}_{\mathrm{i}}$ ) (Fig. 12), and the second comparing estimated total economic activity to GSP or GDP with added informal economy estimates as estimated by Schneider $\left(\right.$ GSPS $_{\mathrm{i}}$ and GDPS $_{\mathrm{i}}$ ) (Fig. 13). 


\begin{tabular}{|c|c|c|c|c|c|c|c|c|}
\hline \multicolumn{3}{|c|}{ LandScan Population $=500$} & \multicolumn{3}{|c|}{ Sum of lights $=50$} & & & \\
\hline 25 & 0 & 50 & 0 & 0 & 5 & & & \\
\hline 75 & 0 & 25 & 0 & 5 & 0 & & & \\
\hline 50 & 100 & 0 & 0 & 10 & 5 & & & \\
\hline 100 & 50 & 25 & 5 & 10 & 10 & & & \\
\hline \multicolumn{3}{|c|}{$\begin{array}{l}\text { Economic activity attributed to } \\
\text { agriculture }(\$ 2,000)\end{array}$} & \multicolumn{3}{|c|}{$\begin{array}{c}\text { Economic activity attributed to } \\
\text { commercial/industrial sector } \\
(\$ 8,000)\end{array}$} & \multicolumn{3}{|c|}{$\begin{array}{l}\text { GDPI grid of total economic } \\
\text { activity, } \sum \text { cells }=\$ 10,000\end{array}$} \\
\hline$\$ 100$ & $\$ 0$ & $\$ 200$ & $\$ 0$ & $\$ 0$ & $\$ 800$ & $\$ 100$ & $\$ 0$ & $\$ 1000$ \\
\hline$\$ 300$ & $\$ 0$ & $\$ 100$ & $\$ 0$ & $\$ 800$ & $\$ 0$ & $\$ 300$ & $\$ 800$ & $\$ 100$ \\
\hline$\$ 200$ & $\$ 400$ & $\$ 0$ & $\$ 0$ & $\$ 1600$ & $\$ 800$ & $\$ 200$ & $\$ 2000$ & $\$ 800$ \\
\hline$\$ 400$ & $\$ 200$ & $\$ 100$ & $\$ 800$ & $\$ 1600$ & $\$ 1600$ & $\$ 1200$ & $\$ 1800$ & $\$ 1700$ \\
\hline
\end{tabular}

Fig. (9). Model illustrating the distribution of Estimated GDPI for a hypothetical country (GDPI $=\$ 10,000$; \% contribution of agriculture towards GDP $=20 \%$ ).

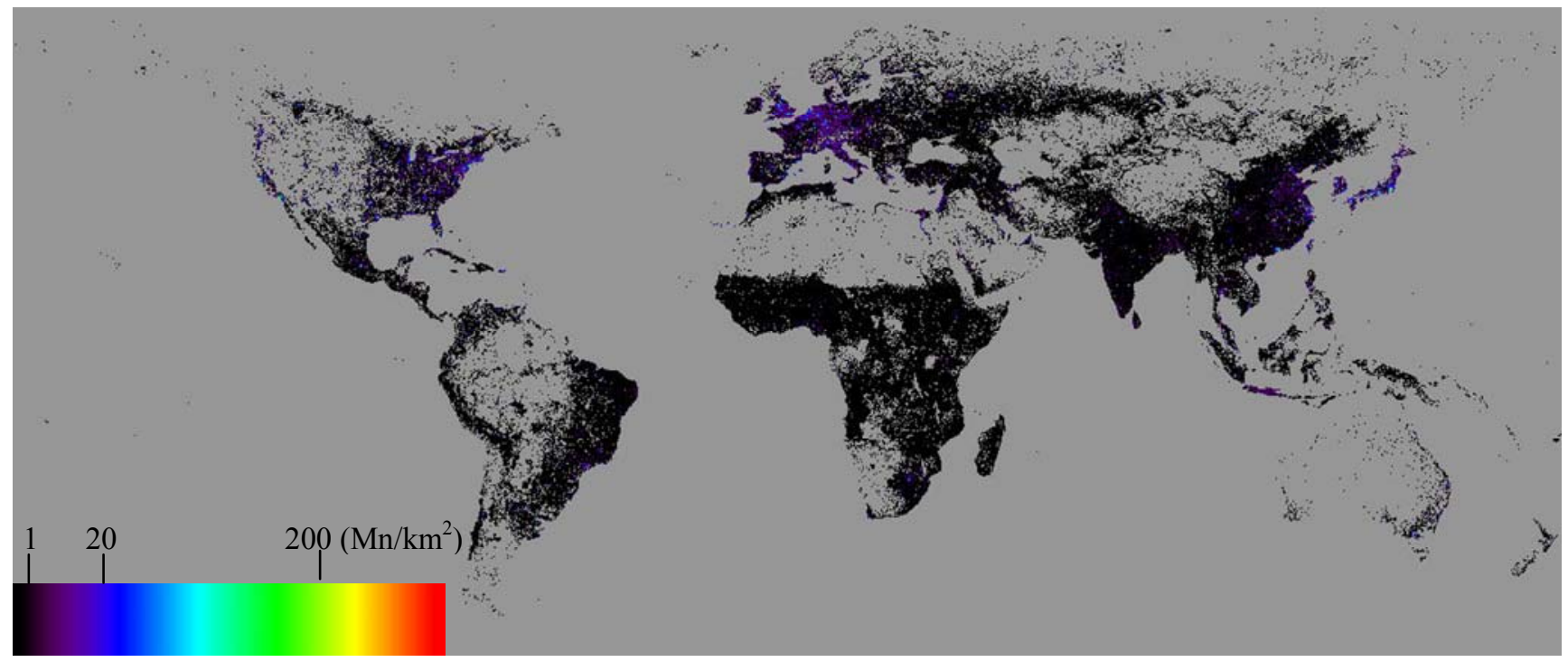

Fig. (10). Grid of total economic activity in millions of dollars per $\mathrm{km}^{2}$ pixel.

Fig. (12) shows that estimated total economic activity was greater than official economic activity for all administrative units. This is expected, as unlike the official economic activity values, the estimated total economic activity values include the informal economy estimates. Estimated $\mathrm{GDPI}_{\mathrm{i}}$ values were thus up to 30 percent higher than the official $\mathrm{GDP}_{\mathrm{i}}$ values, for both developed and developing countries. At the sub-national level, estimated $\mathrm{GSPI}_{\mathrm{i}}$ was greater than official GSP ${ }_{\mathrm{i}}$ by up to 30 percent for all the states of India, Mexico, and the U.S., and for China, GSPI $_{i}$ was greater than $\mathrm{GSP}_{i}$ by up to 21 percent for all but one state (Ningxia). 

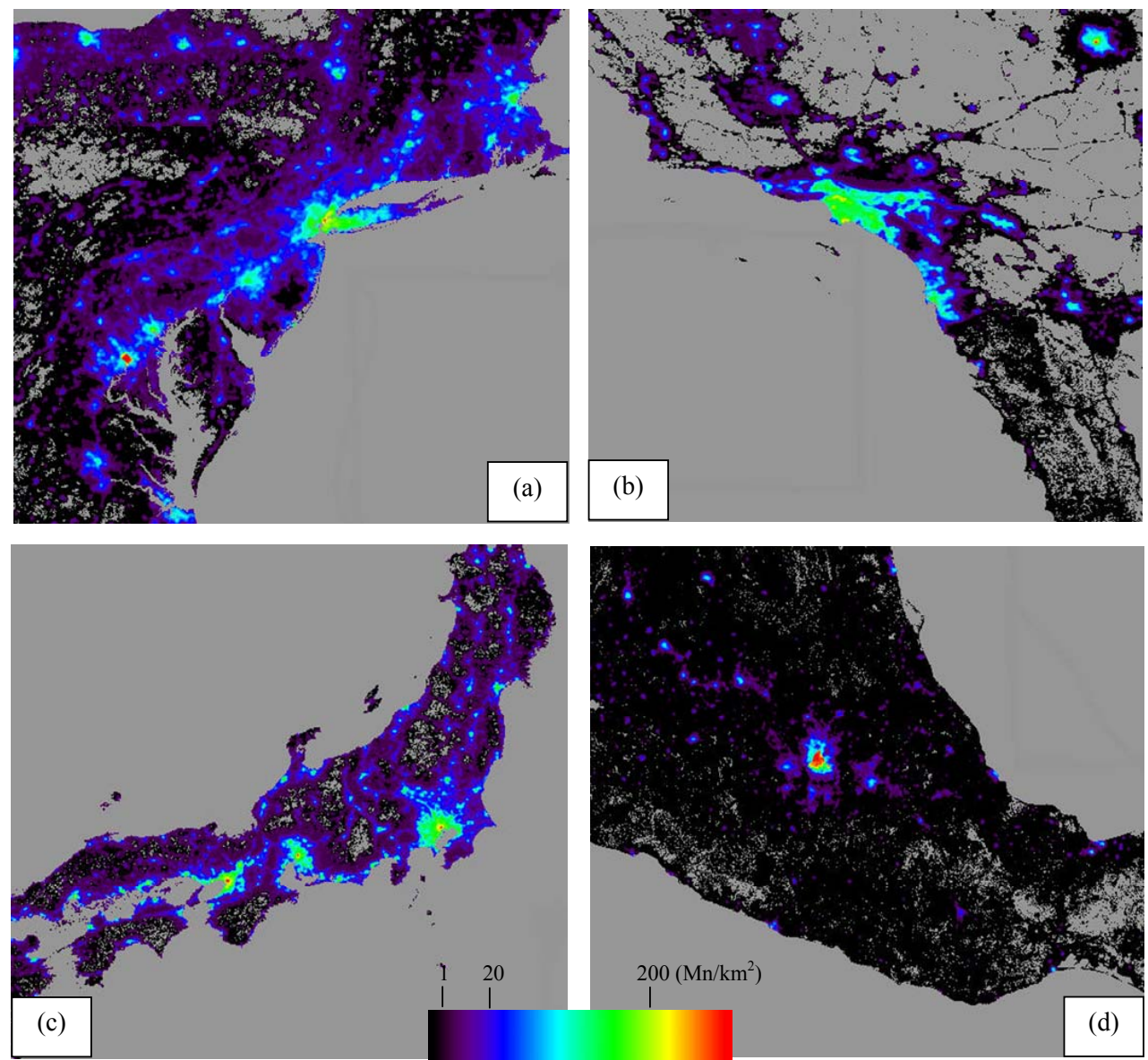

Fig. (11). Grid of total economic activity in millions of dollars per $\mathrm{km}^{2}$ pixel (a) North-eastern United States, (b) South-west California, (c) Japan, (d) Mexico City and surroundings.

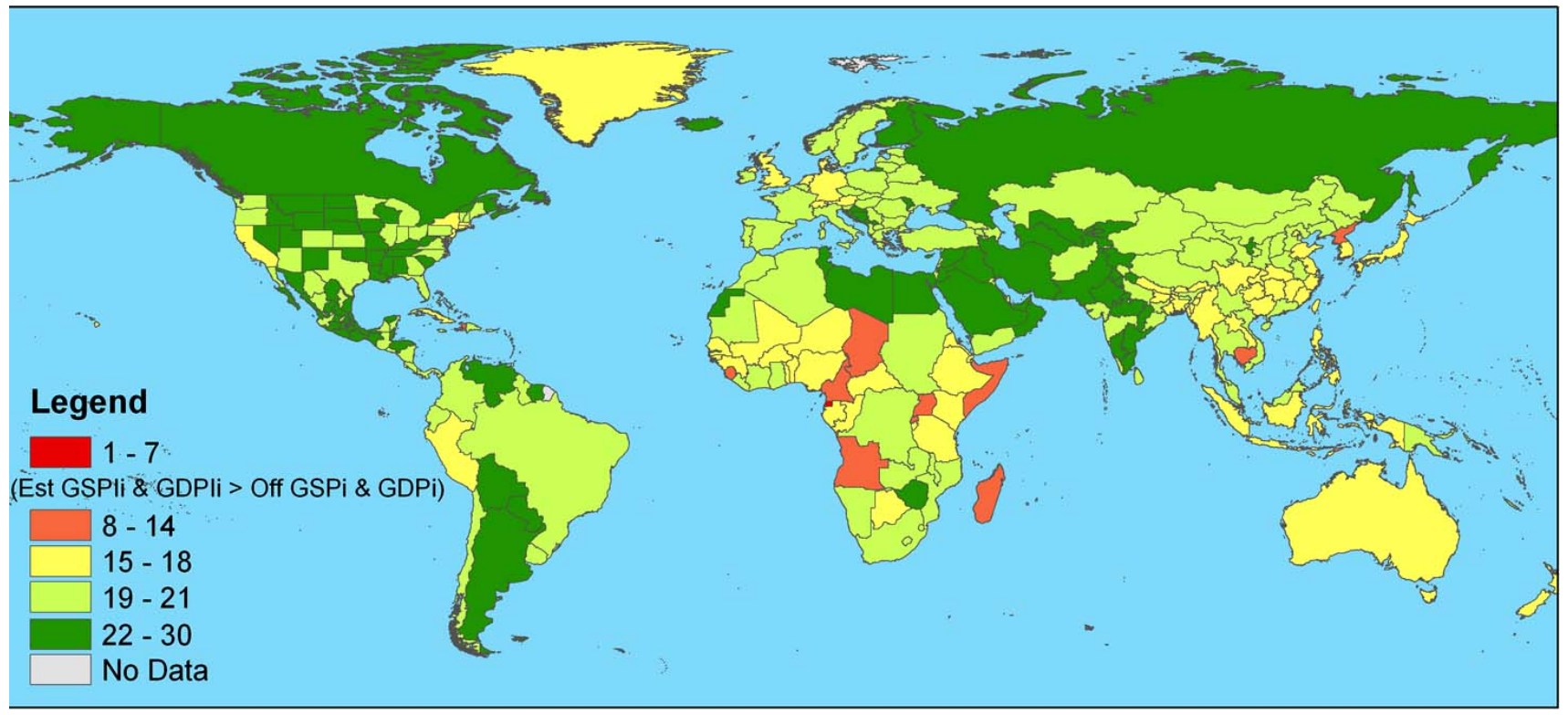

Fig. (12). Percentage difference map of estimated total economic activity and official economic activity.

Since GSPS ${ }_{i}$ and GDPS $_{\mathrm{i}}$ (i.e., GSP and GDP with added Schneider's informal economy estimates) of the administrative units was used to calibrate the model for estimating $\mathrm{GSPI}_{\mathrm{i}}$ and $\mathrm{GDPI}_{\mathrm{i}}$ from the sum of lights, a percentage difference map between estimated $\mathrm{GSPI}_{\mathrm{i}}, \mathrm{GDPI}_{\mathrm{i}}$, and $\mathrm{GSPS}_{i}$, GDPS $_{i}$ was made (Fig. 13). Estimated GDPI $\mathrm{i}_{\mathrm{i}}$ was greater than GDPS $S_{i}$ for almost all the countries (with the exception of many of the African countries, Russia, some of 


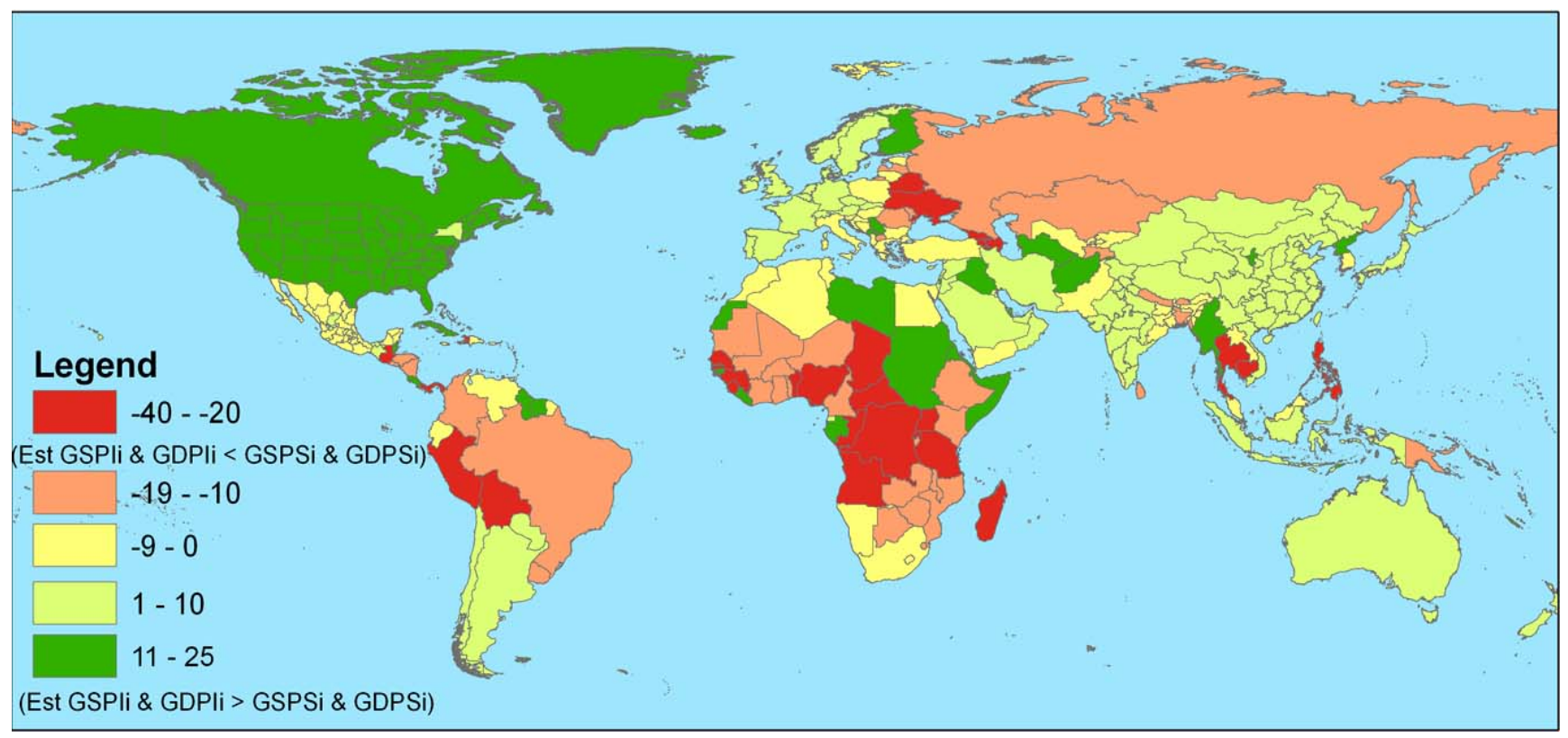

Fig. (13). Percentage difference map of estimated total economic activity and economic activity with added Schneider's informal economy estimates.

the South American countries, and South-east Asian countries) implying that Schneider may have underestimated informal economic activity for those countries. At the subnational level, for most U.S. states, estimated GSPI ${ }_{i}$ was greater than GSPS $_{i}$ up to 25 percent, and for China and India $\mathrm{GSPI}_{\mathrm{i}}$ was greater by up to 10 percent for most states. These results indicate that Schneider may have underestimated the informal economic activity in the U.S., China, and India. For most of the states of the Mexican Republic, however, estimated $\mathrm{GSPI}_{\mathrm{i}}$ was less than $\mathrm{GSPS}_{\mathrm{i}}$, indicating that Schneider may have overestimated the informal economic activity for the Mexican Republic.

\section{DISCUSSION}

A global grid of estimated total economic activity with a spatial resolution of $1 \mathrm{~km}^{2}$ was generated based on the nighttime lights grid and the LandScan population grid. The greatest advantage of the disaggregated GDP map is that it offers immense analytical flexibility, because the data can be aggregated to units of different sizes. This could enable governments and analysts to track the economic growth of regions at different economic units of analysis and to implement appropriate measures and policies. This could also benefit researchers engaged in environmental, physical, or other socio-economic analysis, as they could aggregate the data to different ecological, physical, or social units.

Estimation of economic activity from the nighttime lights helps to overcome many of the problems associated with data collected through surveys, as the nighttime lights dataset are easily available and can be frequently updated. Economic censuses are usually conducted at intervals of 510 years, but the global coverage of nighttime lights data is available on a daily basis, and they are composited on a monthly and annual basis. Hence, nighttime lights data could serve as a proxy measure for estimating GDP for the intercensal years.

The NGDC at NOAA is currently producing merged stable lights and radiance-calibrated products for the years 1996-97, 1999, 2000, 2003, and 2004. NGDC has also received approval from the Air Force for a new round of data collection at low, medium, and high gain settings, and these data will be used to produce a year 2010 radiance-calibrated nighttime lights product and subsequently a merged stablelights and radiance-calibrated product for 2010. The coefficients estimated for 2006 could be used to estimate GDP for the merged nighttime lights product of 2010 and could also make it possible to estimate GDP for past years. Although it can be argued that using the coefficients of 2006 to estimate GDP and GSP of other years is based on the assumption that the ratio of sum of lights to GDP and GSP as being constant over time, the exercise should still be an interesting investigation in itself. Moreover, comparison of GDP and GSP estimates from the nighttime lights to official GDP and GSP statistics of past years and future years may provide useful insights as to the development of nighttime lights as a truly independent proxy measure of economic activity.

Many of the drawbacks which were noticed in some of the previous studies in trying to estimate economic activity from nighttime lights were addressed in this paper. The nighttime lights data which were used for this study were a merged stable lights and radiance-calibrated product, which shows brightness variations within city centers and helps to overcome the problem of saturation of city centers associated with stable lights images. In addition, the use of radiancecalibrated images also enables the detection of dimly lit areas, and therefore more economic activity is detected. 
Doll et al. [4] had noted the necessity of considering agricultural activity in the estimation of the total economic activity of a country. Since agriculture is a spatial activity, it is not only important to consider the percentage contribution of agriculture towards GDP, but also necessary to 'spread' the contribution of agriculture towards GDP in the 'fields'. The present analysis addressed this issue by distributing the percentage contribution of agriculture in the estimated $\mathrm{GDPI}_{\mathrm{i}}$ and $\mathrm{GSPI}_{\mathrm{i}}$ according to the LandScan population grid. Therefore, for countries such as India, China, as well as many of the African countries, where the agricultural contribution towards GDP is considerable, economic activity was distributed in the darker areas of each country, corresponding to rural population areas where there are people engaged in agricultural economic activity but there are no lights.

The approach presented in this paper is not a truly independent measure of economic activity because it still utilizes official GDP and GSP statistics and estimates of the informal economy in order to estimate regression coefficients. These regression coefficients vary dramatically as a function of the ratio of lights to economic activity for any given administrative unit. All previous disaggregated GDP maps which have been created to date using the nighttime lights data have relied on official statistics of GDP $[4,15,16]$. For this paper, efforts were initially made to create the GDP grid using only the nighttime lights image and LandScan population grid. However, countries with large populations and relatively low lighting, such as China and India, defeated all attempts at developing a truly independent method (without relying on official statistics) for estimating economic activity. However, it can be anticipated that future longitudinal research of the relationships between nighttime imagery, population distribution, and the sectoral distribution of economic activity (i.e., agricultural, industrial, and service sectors) might contribute to the development of a more independent means of measuring economic activity from nighttime imagery.

The DMSP-OLS data have observational shortcomings, with coarse spatial and spectral resolution and lack of onboard calibration. These shortcomings will be addressed by the Visible Infrared Imaging Radiometer Suite (VIIRS) which will fly on the National Polar Orbiting Environmental Satellite System (NPOESS) during the next decade. The VIIRS will have on-board calibration and a higher spatial resolution $(0.8 \mathrm{~km})$ and spectral resolution. Nighttime lights data acquired at a higher spatial and spectral resolution will potentially facilitate creation of more accurate socioeconomic maps.

In spite of the shortcomings, the methodology developed here to estimate economic activity using a combination of nighttime satellite data, official measures of GDP and GSP, and informal economy estimates is a useful and innovative initiative. While none of the datasets are free of error, it can be assumed that a combination of several datasets having the 'right' kind of measurement errors might help to minimize the errors of the final product. This assumption is based on Browning and Crossley's [31] study in which they suggested that it is perhaps easier to design socio-economic survey questions with two or more 'right' kind of measurement errors, which provide better information about the distribution of the quantity of interest than attempting to design survey questions without measurement errors. Thus, they rightly concluded: 'It is better to have several errorprone measures than one.'

\section{CONCLUSION}

The global economic recession has stalled the progress towards the achievement of the Millennium Development Goals. It is envisaged that 55 million to 90 million more people will be living in extreme poverty in 2009. The employment situation will worsen with more people joining the vulnerable informal economy. The International Labor Organization estimates that global unemployment in 2009 could reach between 6.3 and 7.1 percent by the end of 2009 [1]. In such a scenario, the need to understand the global distribution of wealth assumes great importance for undertaking appropriate policies and measures for paving the path to economic recovery. The map of total economic activity, including both formal and informal economic activity, created from the nighttime lights and LandScan population grid provide an alternative means for measuring global economic activity which could be updated on an annual or semi-annual basis. Such data could also help to estimate past economic conditions and determine future trends.

\section{ACKNOWLEDGEMENTS}

Very special thanks to Ben Tuttle and Daniel Ziskin of the Earth Observation Group, National Geophysical Data Center, National Oceanic and Atmospheric Administration for their valuable suggestions and technical advice.

\section{REFERENCES}

[1] United Nations. The millennium development goals report. New York: United Nations 2009.

[2] Sachs J. The end of poverty: economic possibilities of our time. New York: The Penguin Press 2005

[3] Sullivan A, Sheffrin SM. Economics: principles in action. Upper Saddle River New Jersey: Pearson Prentice Hall 1996.

[4] Doll CNH, Muller JP, Morley JG. Mapping regional economic activity from night-time light satellite imagery. Ecol Econ 2006; 57: 75-92.

[5] Elvidge CD, Sutton PC, Ghosh T, et al. A global poverty map derived from satellite data. Comput Geosci 2009a; 35: 1652-60.

[6] Min B. Democracy and light: electoral accountability and the provision of public goods. Annual meeting of midwest political Science association. Chicago, Illinois. April 6, 2008.

[7] Henderson JV, Storeygard A, Weil DN. Measuring economic growth from outer space. NBER Working Paper 15199. National bureau of economic research. Cambridge, Massachusetts 2009.

[8] Porter, E. China Shrinks. New York Times. December 9, 2007.

[9] Ebener S, Murray C, Tandon A, Elvidge CD. From wealth to health: modeling the distribution of income per capita at the subnational level using nighttime light imagery. Int $\mathbf{J}$ Health Geogr 2005; 4: 1-17.

[10] Sutton PC, Elvidge CD, Ghosh T. Estimation of gross domestic product at sub-national scales using nighttime satellite imagery. Int J Ecol Econ Stat 2007; 8: 5-21.

[11] Ghosh T, Anderson S, Powell RL, Sutton PC, Elvidge CD Estimation of Mexico's informal economy and remittances using nighttime imagery. Remote Sens 2009; 1(3): 418-44.

[12] International Labor Organization. Women and men in the informal economy: a statistical picture. Geneva: ILO, 2002.

[13] Elvidge CD, Erwin EH, Baugh KE, et al. Overview of DMSP nighttime lights and future possibilities, IEEE proceedings of the 7 th international urban remote sensing conference. Shanghai, China 2009b. 
[14] Elvidge CD, Baugh KE, Kihn EA, Koehl HW, Davis ER, Davis CW. Relation between satellites observed visible near-infrared emissions, population, economic activity and power consumption. Int J Remote Sens 1997; 18: 1373-9.

[15] Doll CNH, Muller JP, Elvidge CD. Nighttime imagery as a tool for global mapping of socioeconomic parameters and greenhouse gas emissions. Ambio 2000; 29(3): 157-62.

[16] Sutton PC, Costanza R. Global estimates of market and non-market values derived from nighttime satellite imagery, land cover, and ecosystem service evaluation. Ecol Econ 2002; 41: 509-27.

[17] Elvidge CD, Baugh KE, Dietz JB, Bland T, Sutton PC, Kroehl HW. Radiance calibration of DMSP-OLS low-light imaging data of human settlements. Remote Sens Environ 1999; 68: 77-88.

[18] LandScan global population database. Oak Ridge, TN: Oak Ridge national laboratory 2006.

[19] World Bank, Development Data Group. 2008 world development indicators online. Washington, DC: The World Bank 2008a.

[20] Central Intelligence Agency World Factbook. Washington, DC, 2006.

[21] World Bank. World Development Report 1994: Infrastructure for Development. New York: Oxford University Press, 1994.

[22] Bureau of economic analysis, U.S. Department of Commerce. Washington, DC 2006.
[23] INEGI. Mexico, D.F., 2006.

[24] National bureau of statistics of China. Beijing, China 2006

[25] Central statistical organization. New Delhi, India, 2006.

[26] Schneider F. Shadow economies and corruption all over the world: new estimates for 145 countries, Open-Assessment E-J 2007-9; Version 1.

[27] Schneider F. Size and measurement of the informal economy in 110 countries around the world. Workshop of Australian national tax center, ANU. Canberra, Australia. July 17, 2002.

[28] Schneider, F. The size of the shadow economy in 21 OECD countries (in \% of "official" GDP) using the MIMIC and currency demand approach: from 1989/90 to 2009. Johannes Kepler Universitat Linz, Austria, 2009a.

[29] Schneider, F. The size of the shadow economy for 25 transition countries over 1999/00 to 2006/07: What do we know? Johannes Kepler Universitat Linz, Austria, 2009b.

[30] World Bank. World development report 2008: agriculture for development. Washington DC: World Bank, 2008b.

[31] Browning M, Crossley T. Are two cheap, noisy measures better than one expensive, accurate one? Am Econ Rev 2009; 99(2): 99108 .

(C) Ghosh et al.; Licensee Bentham Open.

This is an open access article licensed under the terms of the Creative Commons Attribution Non-Commercial License (http://creativecommons.org/licenses/by$\mathrm{nc} / 3.0 /$ ) which permits unrestricted, non-commercial use, distribution and reproduction in any medium, provided the work is properly cited. 